\title{
Field Anesthesia and Health Assessment of Free-ranging Cebus capucinus in Panama
}

\author{
M. C. Crofoot • T. M. Norton • R. G. Lessnau • \\ T. C. Viner • T. C. Chen • L. M. Mazzaro • \\ M. J. Yabsley
}

Received: 2 September 2008 / Accepted: 5 September 2008 /

Published online: 31 January 2009

(C) The Author(s) 2009. This article is published with open access at Springerlink.com

\begin{abstract}
Health and disease are critical factors for understanding primate evolution and for developing effective conservation and management strategies. However, comprehensive health assessments of wild primate populations are rare, in part because of the difficulty and risk of chemically immobilizing subjects to obtain the necessary biological samples. We report here the results of a health assessment, as
\end{abstract}

M. C. Crofoot $(\bowtie)$

Smithsonian Tropical Research Institute, Apartado 0843-03092,

Balboa, Ancón, Panamá, República de Panamá

e-mail: crofootm@si.edu

M. C. Crofoot

Department of Migration and Immuno-ecology, Max Planck Institute for Ornithology, Schlossallee 2,

D-78315 Radolfzell, Germany

T. M. Norton

St. Catherine's Island Foundation, Midway, GA 31320, USA

R. G. Lessnau

Detroit Zoological Society, Royal Oak, MI 48067, USA

T. C. Viner

Department of Pathology, Smithsonian National Zoological Park, Washington, DC 20008, USA

T. C. Chen

Section of Endocrinology, Diabetes and Nutrition, Boston University School of Medicine, Boston, MA 02218, USA

L. M. Mazzaro

Mystic Aquarium and Institute for Exploration, Mystic, CT 06355, USA

M. J. Yabsley

Warnell School of Forestry and Natural Resources, University of Georgia, Athens, GA 30602, USA

M. J. Yabsley

Southeastern Cooperative Wildlife Disease Study, Department of Population Health,

College of Veterinary Medicine, University of Georgia, Athens, GA 30602, USA 
well as the methods and drug dosages used to capture white-faced capuchins (Cebus capucinus) on Barro Colorado Island, Panama. We captured and measured 24 capuchins as part of an ongoing radiotelemetry study, and collected biological samples from 9 of them for a comprehensive health survey. Telazol ${ }^{\circledR}$ was very effective for immobilizing and capturing capuchins, although the doses we used were higher than those recommended for captive capuchins. High Telazol doses immobilized individuals quickly, ensuring that we were able to find and recover the sedated monkeys. The capuchins were generally in good condition, and had few ecto-, hemo-, or intestinal parasites. However, all but 1 of the adults had substantial dental abnormalities. In addition, 1 juvenile had indeterminate genitalia that we believe to be the result of hypospadias. Seven of the capuchins tested positive for exposure to Herpesvirus tamarinus and all individuals tested positive for exposure to Cebus cytomegalovirus. Hematology, serum chemistry, and plasma mineral levels from the wild individuals were, for the most part, comparable to those recorded for captive Cebus capucinus, and contribute to establishing baseline health values for the species.

Keywords Barro Colorado Island · chemical immobilization · darting · disease · hematology $\cdot$ serology $\cdot$ Telazol

\section{Introduction}

Health and disease play critical but poorly understood roles in the evolution of primate behavior, social organization, and demography (Alexander 1974; Kappeler and van Schaik 2002; Loehle 1995; Moller et al. 1993). They also present major conservation concerns. Many primate species live in small, fragmented populations where the effects of disease may be particularly devastating (Junge and Louis $2005 \mathrm{~b}$ ). Evaluating the incidence and prevalence of disease in these populations is essential for designing successful management and conservation strategies (Daszak et al. 2000; Deem et al. 2001; Karesh and Cook 1995; May 1988; Morner et al. 2002; Scott 1988; Spalding and Forrester 1993; Williams et al. 2002; Wobeser 2002). Such evaluations are particularly important in areas like research sites, where frequent contact between humans and wild primates increases the likelihood of zoonotic disease transmission (Kondgen et al. 2008). In addition to providing essential data for monitoring the long-term well-being of primate populations (Karesh et al. 1998), baseline health data may also provide important insight into the effects of health and disease on individual fitness.

Despite its theoretical and practical importance, few studies have explicitly focused on health in wild primate populations. Several researchers have investigated the prevalence of specific diseases within and across species, e.g., malaria (Davies et al. 1991; Nunn and Heymann 2005), but baseline data on the general health parameters of wild individuals are known for relatively few species: Propithecus tattersalli (Garell and Meyers 1995), Ateles paniscus chamek (Karesh et al. 1998), Aloutta seniculus (Vie et al. 1998), Pithecia pithecia and Saguinus midas (de Thoisy et al. 2001), Lemur catta (Dutton et al. 2003), Varecia variegata and V. rubra (Junge and Louis 2005b), Propithecus verreauxi deckeni and Eulemur fulvus rufus (Junge and Louis 2005a), and E. macaco macaco (Junge and Louis 2007). 
One can obtain the samples required to conduct a wildlife health analysis only by capturing wild animals. Chemically immobilizing and handling wild primates always includes a degree of risk for the subjects and researchers. The paucity of published information on appropriate drug dosages and on the reactions of primates to the most commonly used drugs exacerbates the risk. Karesh et al. (1998) have recommended that health assessments be conducted whenever wild primates are immobilized for research purposes. Accordingly, we collected biological samples from white-faced capuchins (Cebus capucinus) on Barro Colorado Island, Panama, that were captured and fit with radiocollars as part of a larger study on intergroup relationships. Here we report the results of the wildlife health analysis, as well as the methods and drug doses used to immobilize and capture the capuchins.

\section{Methods}

We captured 24 white-faced capuchins (Cebus capucinus) from 6 different social groups between July, 2004 and September, 2005 at the Smithsonian Tropical Research Institute on Barro Colorado Island, Panama. We conducted 3 separate rounds of darting, with 10 individuals captured from July 30 to August 6, 2004; 5 individuals captured from February 21 to 25, 2005; and 9 individuals captured from September 4 to 9, 2005 (Table I). We fitted 9 of the individuals captured during the first round with radiocollars to track their movements as part of a project on ranging behavior and intergroup competition (Crofoot 2007; Crofoot et al. 2008; Wrangham et al. 2007). We conducted the second round of darting to place additional radiocollars in undersampled groups and to replace 2 collars that had malfunctioned. We were unable to recapture the 2 individuals whose collars had malfunctioned, but we captured and fitted 5 additional individuals with radiocollars. The intent of the third round of darting was to remove the collars and collect blood and fecal samples for health assessment. Our attempts to recapture collared individuals were unsuccessful, but we captured 9 additional individuals for the health assessment portion of this project.

\section{Capture Methods}

We immobilized capuchins with Telazol ${ }^{\circledR}(50 \mathrm{mg} / \mathrm{ml}$ of tiletamine hydrochloride, $50 \mathrm{mg} / \mathrm{ml}$ of zolazepam hydrochloride; Fort Dodge Animal Health, Fort Dodge, IA),

Table I Data collection schedule

\begin{tabular}{llll}
\hline & Dates & Individuals captured & Data collected \\
\hline Round 1 & July 30-Aug. 6, 2004 & 5 males & $\begin{array}{l}\text { Masses } \\
\text { Morphometrics } \\
\text { Whole blood } \\
\text { Round 2 }\end{array}$ \\
& Feb. 21-25, 2005 & 5 females & Masses \\
& & & Morphometrics \\
& & & Whole blood \\
Round 3 & Sept. 4-9, 2005 & 3 males & Masses \\
& & 3 females & Morphometrics \\
& & 3 juveniles & Biological samples \\
\hline
\end{tabular}


a nonnarcotic, nonbarbiturate, injectable anesthetic (Table II). The first 2 individuals that we sedated salivated heavily and all subsequent darts contained atropine (2.25$3 \mathrm{mg}$ ) to prevent hypersalivation $(0.54 \mathrm{mg} / \mathrm{ml}$ of atropine sulfate; Phoenix Scientific, St. Joseph, MO). We delivered anesthesia via a Pneu-Dart ${ }^{\mathrm{TM}} \mathrm{CO}_{2}$ gun (Pneu-Dart, Williamsport, PA) using disposable, nonbarbed, 1-cc or 0.5 -cc darts with a $3 / 8$-in. needle. We targeted the muscles of the hindquarters and did not attempt darting unless the individual was facing away from the shooter to avoid hitting unsuitable portions of the body such as the face, neck, chest, and abdomen (Glander et al. 1991).

After we darted a capuchin, we monitored its movements visually but did not approach until the anesthesia had started to take effect because approaching too quickly caused individuals to flee. After the initial startle due to the darting, capuchins tended to move only a few meters before becoming drowsy. We were then able to position outstretched hammocks underneath the sedated individual and catch it as it lost its ability to grip a substrate. We caught 13 of the 24 individuals in hammocks; the remaining subjects fell and we recovered them from the ground. Two monkeys were injured during the darting process. One individual had a nondisplaced fractured femur, and we held her overnight to ensure she had completely recovered from the anesthetic before being released. We monitored her condition twice a week over the next 2 mo. The second injured capuchin had partial paralysis of the forelimbs, and received emergency care in the field before being transported to the University of Panama, School of Veterinary Medicine for further care. Both individuals recovered completely and were living in their original social groups at the end of the 14-month study.

We processed all subjects in the field where we captured them. Once each subject was on the ground, we immediately took its respiratory rate, heart rate, and body temperature. We cleaned the dart site and any injuries that occurred during capture with dilute Betadine or alcohol and a topical antibiotic ointment. We examined and measured sedated monkeys, and, during the third round of darting, collected biomedical samples. We recorded heart rate, respiratory rate, and body temperature every 5-10 min. Capuchins recovered from anesthesia in burlap or canvas bags in the shade until they were active and able to climb unassisted.

\section{Physical Examination and Measurements}

We performed a complete physical examination on each subject. We identified individuals as adults based on the presence of full permanent dentition. We measured body mass with a 10-kg Pesola ${ }^{\circledR}$ scale (Pesola AG, Baar, Switzerland) and took morphometric measurements including body length, tail length, arm length, leg length, hind foot length, big toe length, thumb length, neck circumference, and testicle length and width (Glander et al. 1991).

During the first 2 rounds of darting, we fitted each monkey with a radiocollar of tubular nylon, adjustable between 13 and $19 \mathrm{~cm}$ circumference (Advanced Telemetry Systems, Isanti, MN). The collars weighed $41 \mathrm{~g}$, which is $<2 \%$ of an adult female's body mass, and is within the recommended limit of 5\% of a subject's body mass (Macdonald and Amlaner 1980). 


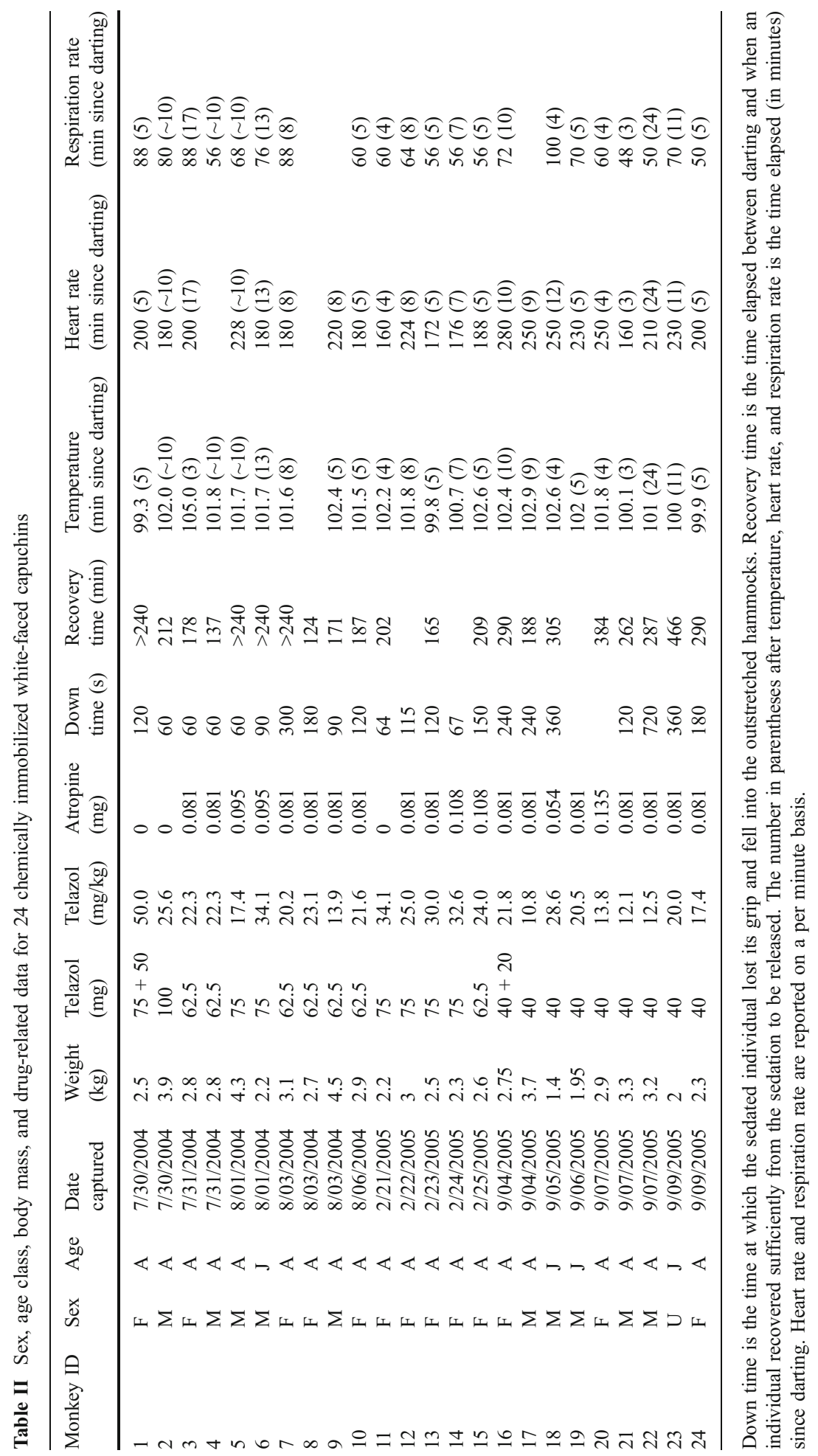


We collected blood samples from the femoral vein. The volume of blood was $\leq 1 \%$ of the body mass $(1 \mathrm{ml} / 100 \mathrm{~g}$ body mass $)$. We placed whole blood $(0.5 \mathrm{ml})$ into an ethylenediamine tetraacetic acid (EDTA) anticoagulant tube, a trace-metal-free blood collection tube, and the remaining volume into nonanticoagulant serum separator tubes and allowed it to clot. We kept the blood cool on ice packs until processing. We centrifuged serum tubes $\leq 4 \mathrm{~h}$ after collection. We transferred sera to $1.8-\mathrm{ml}$ cryotubes, and immediately placed them into a $-70^{\circ} \mathrm{C}$ freezer. We maintained blood and serum in a frozen state during transport to the United States and subsequently stored them at $-70^{\circ} \mathrm{C}$ until analysis.

We prepared 4 smears from the EDTA blood, within $10 \mathrm{~min}$ of collection. We then dried the smears and fixed them in methanol. We later stained slides with WrightGiemsa, examined them microscopically for parasites, and used them for differential white blood cell counts. We performed a total white blood cell count $\leq 8 \mathrm{~h}$ after collection, via a hemocytometer and the Unopette staining system (Becton-Dickson, Rutherford, NJ). We transferred a small amount of EDTA whole blood to a microhematocrit tube and centrifuged it using a battery-powered microhematocrit centrifuge (HemataStat II, Separation Technology) to measure packed cell volume (PCV). We measured plasma total solids via refractometer adjusted for room temperature before each use.

After we transported the serum to the United States, the clinical pathology laboratory at the Smithsonian's National Zoological Park in Washington, DC processed it. We performed biochemical profiles on serum samples using a Roche Cobas Mira Plus chemistry analyzer. The following blood values were measured: glucose, sodium, potassium, blood urea nitrogen (BUN), creatinine, BUN/creatinine ratio, phosphorus, calcium, creatine phosphokinase (CPK), alanine aminotransferase (ALT), aspartate aminotransferase (AST), total bilirubin, alkaline phosphatase, bicarbonate, chloride, total protein, albumin, and globulin.

We submitted serum to a commercial laboratory (VRL Laboratories, San Antonio TX) for viral serology analysis for the following agents: Herpesvirus tamarinus, H. samari, measles, and Cebus cytomegalovirus. In addition, we performed nested polymerase chain reaction assays on whole blood from all 24 individuals for Trypanosoma cruzi and piroplasms per Yabsley et al. (2006) and Roellig et al. (in press).

For nutritional evaluation, we analyzed serum for fat-soluble vitamins. We measured serum 25-hydroxycholecalciferol [25(OH)D] via competitive protein binding assay (Chen et al. 1990). We determined serum vitamin A (retinol) and vitamin $\mathrm{E}$ ( $\alpha$-tocopherol) concentrations via reversed phase high-performance liquid chromatography (HPLC) at the Department of Nutrition at the Mystic Aquarium (Mystic, CT). We measured copper, iron, calcium, total phosphorus, potassium, sodium, and zinc from serum retrieved from the trace-metal-free tubes by inductively coupled argon plasma-mass spectrometry (ICP-MS) at the University of Pennsylvania College of Veterinary Medicine Toxicology Laboratory. We measured each metal or mineral along with blanks, standards, and a standard reference material containing known amounts of the metals or minerals of interest.

We collected fecal samples directly from the rectum. We could not obtain samples from all subjects. We stored feces into $10 \%$ formalin for future examination for 
parasite ova at the Smithsonian's National Zoological Park. We used direct prep methods to look for protozoa, and modified Sheather's sugar flotation techniques to look for nematode eggs. If sufficient feces were available, we placed them in enrichment media (Fisher Diagnostics, Middletown, VA), froze them at $-70^{\circ} \mathrm{C}$, and later submitted the samples for enteric bacterial pathogen culture at the University of Georgia, College of Veterinary Medicine Diagnostic Laboratory.

\section{Results}

Immobilization, Measurements, and Collaring

We successfully captured 24 capuchins in $19 \mathrm{~d}$ of darting. Animals received an average Telazol dose of $23.1 \mathrm{mg} / \mathrm{kg}$ (Table II). However, we administered significantly lower doses in the last round of darting than in the first 2 rounds (round 1 and 2 average $=26.3 \mathrm{mg}$ of Telazol $/ \mathrm{kg}$ and round 3 average $=17.5 \mathrm{mg}$ of Telazol $/ \mathrm{kg}, t=2.365, p=0.028$ ). We reduced the dosage during our last round of darting in an attempt to shorten the recovery periods of the sedated subjects. Both the high and low doses induced deep levels of anesthesia, including complete muscle relaxation and loss of reflexes in all but 1 individual. A $2.7-\mathrm{kg}$ female, which we anesthetized with a dart containing $62.5 \mathrm{mg}$ of Telazol, remained alert and responsive, although slightly sedated, throughout the procedure. We weighed and collared her, but did not take other measurements. The failure of this female to reach a deep plane of anesthesia may have reflected an idiosyncratic response to the Telazol, but it is also possible that some of the drug leaked out of the dart such that she did not receive the full dose.

Reducing Telazol dosage increased the time it took for individuals to become immobilized and lose their grip. Including all 3 rounds of darting, the average time from darting to capture was $176 \mathrm{~s}$. The average in the first 2 rounds was significantly shorter than in the last round (round 1 and $2=150 \mathrm{~s}$, round $3=317$ seconds, $Z=-$ $3.158, p=0.002$ ). However, there was not a significant difference in the recovery time between darting rounds (entire study $=288 \mathrm{~min}$, rounds 1 and $2=276 \mathrm{~min}, n=9$, round $3=309$ minutes, $n=8, Z=-1.236, p=0.217$ ).

Morphometric measurements are shown in Table III. On average, adult males in this study are 1.34 times heavier than females (average male weight $=3.6 \mathrm{~kg}, n=7$; average female weight $=2.7, n=13 ; 1$-tailed $t$-test, unequal variance, $p=0.02$ ). They are also significantly longer; the average crown-rump length for adult males is $398 \mathrm{~mm}(n=7)$ whereas the average for females is $372 \mathrm{~mm}(n=11$; 1-tailed t-test, unequal variance $p=0.04)$. However, tail length, arm length, and neck circumference do not differ between the sexes (Table III).

In the first 2 rounds of darting, we fitted 14 individuals from 6 different social groups with radiocollars (10 females, 4 males). The collars did not appear to have a long-term impact on behavior or mobility based on extensive observations. Initially, monkeys responded strongly to the collars, pulling at them and trying to remove them. Within several hours, this behavior was greatly reduced, and within 2 wk it had stopped entirely. 
Table III Morphometric measurements

\begin{tabular}{lcccccc}
\hline & Females & $n$ & Males & $n$ & Juveniles & $n$ \\
\hline Weight (kg) & $2.7 \pm 0.3(2.2-3.1)$ & 13 & $3.5 \pm 0.8(2.2-4.5)$ & 7 & $1.8 \pm 0.3(1.4-2.0)$ & 3 \\
Crown-rump length (mm) & $372 \pm 16(350-400)$ & 11 & $391 \pm 36(340-435)$ & 7 & $324 \pm 8(320-333)$ & 3 \\
Tail length (mm) & $453 \pm 49(335-525)$ & 12 & $473 \pm 17(440-490)$ & 7 & $449 \pm 20(430-470)$ & 3 \\
Arm length (mm) & $289 \pm 12(263-310)$ & 12 & $305 \pm 25(260-340)$ & 7 & $277 \pm 20(255-295)$ & 3 \\
Chest circumference (mm) & $257 \pm 19(230-280)$ & 8 & $290 \pm 43(228-325)$ & 3 & & \\
Right testis length (mm) & & & $21 \pm 3(18-25)$ & 7 & & \\
Right testis width (mm) & & & $21 \pm \pm 3(12-20)$ & 7 & \\
Left testis length (mm) & & & $15 \pm 2(13-19)$ & 6 & \\
Left testis width (mm) & $136 \pm 15(120-160)$ & 8 & $150 \pm 18(130-165)$ & 3 & $108 \pm 6(105-115)$ & 3 \\
Neck circumference (mm) & $380 \pm 20(360-400)$ & 3 & $375 \pm 18(360-395)$ & 3 & $357 \pm 30(325-385)$ & 3 \\
Hind leg length (mm) & $29 \pm 2(27-31)$ & 3 & $28 \pm 3(25-30)$ & 3 & $31 \pm 1(30-32)$ \\
Big toe length (mm) & $127 \pm 4(122-130)$ & 3 & $132 \pm 3(130-135)$ & 3 & $114 \pm 12(100-122)$ & 3 \\
Hind foot length (mm) & $28 \pm 4(25-32)$ & 3 & $29 \pm 3(25-31)$ & 3 & $26 \pm 1(25-27)$ & 3 \\
Thumb length (mm) & & & & & \\
\hline
\end{tabular}

Results are means \pm S.D. (range) of white-faced capuchins on Barro Colorado Island, Panama.

\section{Health Findings}

We conducted systematic physical examinations on the 9 individuals captured in the third round of immobilizations (Table IV); 8 of them were in good overall condition. One lactating female was in poor condition. She may have been pregnant, because inspection of her abdomen and uterus via digital rectal palpation revealed an unidentified mass. All her canines were fractured at the tip, but the fractures did not appear to extend into the tooth's pulp chamber.

Five of the capuchins were either missing teeth or showed substantial dental wear or fractures (Table IV). Missing or broken canines were the most common dental anomaly, although 2 individuals were also missing incisors. In addition, all but 1 individual had healing wounds, many of which appeared to be bite wounds from other capuchins. An adult male had deviated, swollen fingers, and 2 adult females had prominences on their distal tails, consistent with healed fractures. We found botfly larvae (Cuterebra spp.) on 2 females. Finally, 1 of the juveniles had ambiguous genitalia. We suspect that the juvenile was a male with hypospadias, a developmental anomaly of the penis (Fig. 1). Hypospadias is characterized by a defect in the wall of the urethra such that the canal is open for a greater or lesser distance on the undersurface of the penis.

Results of the hematological tests, plasma chemistry, and enzyme and mineral analyses are provided in Table V. The results of serological tests for infectious diseases, whole blood PCR for hemoparasites, and fecal cultures for bacterial infections are provided in Table VI. Seven individuals tested positive for exposure to Herpesvirus tamarinus and all were positive for Cebus cytomegalovirus (Cebus CMV). All subjects were negative for Herpesvirus saimiri, measles, Trypanosoma cruzi, and piroplasms. Fecal cultures were negative for Salmonella, Shigella, and Yersinia, but 5 individuals tested positive for Campylobacter infection based on bacterial culture and polymerase chain reaction (PCR). Seven of the 9 individuals sampled (78\%) had parasites or parasite ova in their feces (Table VII) 
Table IV Summary of physical examination of the nine white-faced capuchins captured during the third round of darting

\begin{tabular}{|c|c|c|c|c|c|}
\hline ID & $\begin{array}{l}\text { Body } \\
\text { score }\end{array}$ & External appearance & Dental & Musuloskeletal & Other \\
\hline 16 & $2.25 / 5$ & $\begin{array}{l}\text { Healed tear in nares } \\
\text { Dermatitis on lower } \\
\text { lip }\end{array}$ & $\begin{array}{l}\text { Heavy wear, canines } \\
\text { broken, missing left } \\
\text { lower incisor, left } \\
\text { upper canine }\end{array}$ & $\begin{array}{l}\text { Prominence } \\
\text { on distal tail }\end{array}$ & Good \\
\hline 17 & $2.5 / 5$ & Wound on base of clavicle & $\begin{array}{l}\text { Upper incisors and } \\
\text { canines missing, } \\
\text { broken bottom } \\
\text { canines }\end{array}$ & $\begin{array}{l}\text { Some fingers } \\
\text { swollen and } \\
\text { deviated }\end{array}$ & Good \\
\hline 18 & & $\begin{array}{l}\text { Healing laceration } \\
\text { lateral to spine }\end{array}$ & Good & Good & $\begin{array}{l}\text { Prominent symmetrical } \\
\text { lymph nodes } \\
\text { in the inguinal }\end{array}$ \\
\hline 19 & $2.25 / 5$ & $\begin{array}{l}\text { Healing wounds on } \\
\text { lower abdomen }\end{array}$ & $\begin{array}{l}\text { Missing left upper } \\
\text { canine }\end{array}$ & Good & $\begin{array}{l}\text { Prominent lymph } \\
\text { nodes }\end{array}$ \\
\hline 20 & $2.5 / 5$ & $\begin{array}{l}\text { Puncture wounds } \\
\text { (possibly bite wounds) } \\
\text { on left side }\end{array}$ & Good & Good & $\begin{array}{l}\text { Lymph nodes } \\
\text { swollen, lactating }\end{array}$ \\
\hline 21 & $2.5 / 5$ & $\begin{array}{l}\text { Puncture wounds } \\
\text { (possibly bite wounds) } \\
\text { on right side of } \\
\text { abdomen }\end{array}$ & Good & Good & Good \\
\hline 22 & $2.5 / 5$ & Healing scrape & $\begin{array}{l}\text { Missing right upper } \\
\text { incisor }\end{array}$ & Good & $\begin{array}{l}\text { Sub-mandibular } \\
\text { swelling }\end{array}$ \\
\hline 23 & $2.25 / 5$ & $\begin{array}{l}\text { Healing wound } \\
\text { in cervical region }\end{array}$ & Good & Good & $\begin{array}{l}\text { Indeterminate } \\
\text { genitalia }\end{array}$ \\
\hline 24 & $2 / 5$ & $\begin{array}{l}\text { Puncture wounds on } \\
\text { right lower chest, } \\
\text { right lateral mid-back, } \\
\text { and below her right } \\
\text { teat }\end{array}$ & All canines broken & $\begin{array}{l}\text { Prominence } \\
\text { on distal tail }\end{array}$ & $\begin{array}{l}\text { Lactating, possibly } \\
\text { pregnant, vestigial } \\
\text { teat on left side }\end{array}$ \\
\hline
\end{tabular}

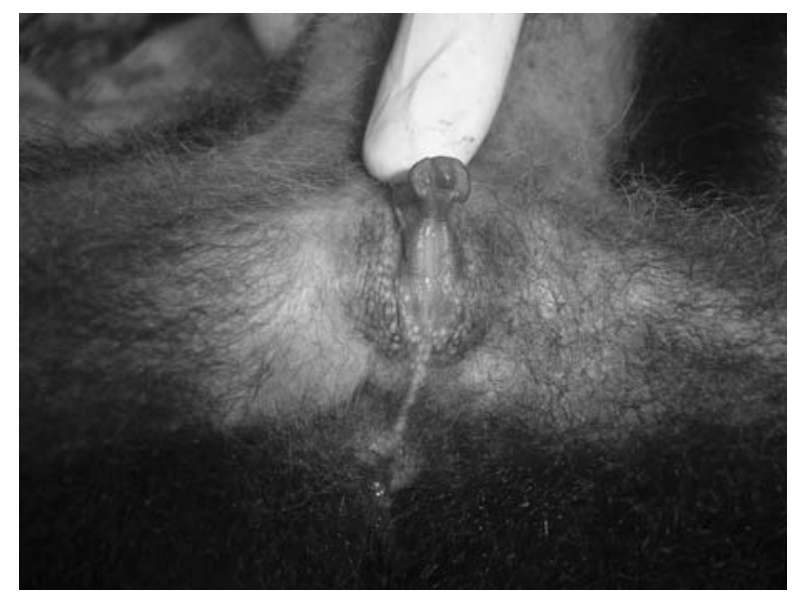

Fig. 1 Ambiguous genitalia of juvenile 23. We think that this individual is a male with hypospadias, a developmental anomaly in which the urinary meatus occurs along the bottom side, rather than at the tip, of the glans penis. 
Table V Hematology, serum chemistry, and mineral and vitamin level findings for 9 wild white-faced capuchins on Barro Colorado Island, Panama

\begin{tabular}{|c|c|c|c|c|}
\hline & All $(n=9)$ & Females $(n=3)$ & Males $(n=3)$ & Juveniles $(n=3)$ \\
\hline \multicolumn{5}{|l|}{ Hematology } \\
\hline Packed cell volume (\%) & $37.6 \pm 3.7$ & $34.9 \pm 3.3$ & $41.3 \pm 1.0$ & $36.4 \pm 3.2$ \\
\hline White blood cells (thousands $/ \mathrm{mm}^{3}$ ) & $5834 \pm 951.5$ & $6812.9 \pm 232.3$ & $4840.0 \pm 305.3$ & $5850.4 \pm 746.4$ \\
\hline Segmented neutrophils (\% WBC) & $37.5 \pm 4.6$ & $38.0 \pm 6.2$ & $38.3 \pm 5.1$ & $35.5 \pm 2.1$ \\
\hline Lymphocytes (\% WBC) & $48.2 \pm 8.3$ & $45.3 \pm 3.1$ & $50.3 \pm 8.0$ & $48.7 \pm 13.6$ \\
\hline Monocytes (\% WBC) & $4.4 \pm 1.9$ & $5.3 \pm 1.5$ & $3.3 \pm 1.5$ & $4.7 \pm 2.5$ \\
\hline Eosinophils (\% WBC) & $8.1 \pm 5.7$ & $11.3 \pm 8.1$ & $7.7 \pm 4.2$ & $4.0 \pm 0.0$ \\
\hline Basophils (\% WBC) & $0.3 \pm 0.5$ & $0.0 \pm 0.0$ & $0.3 \pm 0.6$ & $0.5 \pm 0.7$ \\
\hline \multicolumn{5}{|l|}{ Serum chemistry } \\
\hline Glucose (mg/dl) & $86.6 \pm 18.4$ & $88.0 \pm 16.6$ & $80.7 \pm 30.7$ & $91.0 \pm 7.2$ \\
\hline Blood urea nitrogen (mg/dl) & $14.3 \pm 5.6$ & $12.7 \pm 1.5$ & $14.0 \pm 1.0$ & $16.3 \pm 10.5$ \\
\hline Creatinine (mg/dl) & $0.8 \pm 0.1$ & $0.8 \pm 0.1$ & $0.8 \pm 0.2$ & $0.7 \pm 0.1$ \\
\hline BUN/creatinine ratio & $19.6 \pm 10.4$ & $16.7 \pm 3.1$ & $17.6 \pm 4.4$ & $24.5 \pm 18.6$ \\
\hline Total protein $(\mathrm{g} / \mathrm{dl})$ & $7.9 \pm 1.2$ & $8.4 \pm 1.3$ & $8.7 \pm 0.3$ & $6.7 \pm 0.4$ \\
\hline Albumin $(\mathrm{g} / \mathrm{dl})$ & $3.8 \pm 0.5$ & $3.6 \pm 0.8$ & $3.9 \pm 0.3$ & $3.7 \pm 0.4$ \\
\hline Bilirubin (mg/dl) & $0.4 \pm 0.4$ & $0.5 \pm 0.6$ & $0.5 \pm 0.5$ & $0.2 \pm 0.1$ \\
\hline Alkaline phosphatase (U/L) & $174.4 \pm 98.2$ & $90.0 \pm 20.7$ & $150.7 \pm 34.0$ & $282.7 \pm 88.6$ \\
\hline Alanine aminotransferase (U/L) & $5.8 \pm 2.9$ & $3.3 \pm 2.3$ & $7.0 \pm 2.6$ & $7.0 \pm 2.6$ \\
\hline Aspartate aminotransferase (U/L) & $14.1 \pm 14.3$ & $7.7 \pm 3.1$ & $11.7 \pm 5.5$ & $23.0 \pm 24.2$ \\
\hline Creatine phosphokinase (U/L) & $240.2 \pm 79.9$ & $191.0 \pm 32.5$ & $288.7 \pm 121.0$ & $241.0 \pm 51.6$ \\
\hline Bicarbonate (mmol/L) & $13.3 \pm 4.8$ & $12.3 \pm 3.2$ & $16.0 \pm 7.9$ & $11.7 \pm 2.1$ \\
\hline Calcium (mg/dl) & $8.3 \pm 0.6$ & $7.9 \pm 0.5$ & $8.7 \pm 0.7$ & $8.4 \pm 0.5$ \\
\hline Phosphorus (mg/dl) & $4.6 \pm 1.8$ & $3.6 \pm 1.7$ & $4.6 \pm 1.3$ & $5.6 \pm 2.2$ \\
\hline Sodium $(\mathrm{mmol} / \mathrm{L})$ & $145.7 \pm 1.5$ & $145.7 \pm 2.5$ & $146.3 \pm 1.2$ & $145.0 \pm 0.0$ \\
\hline Potassium (mmol/L) & $4.7 \pm 0.9$ & $5.3 \pm 0.6$ & $4.9 \pm 0.9$ & $3.8 \pm 0.6$ \\
\hline Chloride (mmol/L) & $116.0 \pm 1.1$ & $116.3 \pm 1.5$ & $115.7 \pm 1.2$ & $116.0 \pm 1.0$ \\
\hline \multicolumn{5}{|l|}{ Nutritional minerals } \\
\hline Calcium (ppm) & $105.2 \pm 5.0$ & $102.1 \pm 5.5$ & $109.3 \pm 1.5$ & $104.3 \pm 5.1$ \\
\hline Copper (ppm) & $1.58 \pm 0.11$ & $1.58 \pm 0.14$ & $1.56 \pm 0.11$ & $1.61 \pm 0.13$ \\
\hline Iron (ppm) & $2.87 \pm 1.39$ & $2.78 \pm 1.30$ & $3.19 \pm 1.77$ & $2.63 \pm 1.64$ \\
\hline Magnesium (ppm) & $22.6 \pm 1.4$ & $22.2 \pm 0.9$ & $22.6 \pm 1.5$ & $22.9 \pm 2.0$ \\
\hline Total phosphorus (ppm) & $131.7 \pm 24.3$ & $124.0 \pm 11.8$ & $134.3 \pm 25.5$ & $136.7 \pm 37.8$ \\
\hline Potassium (ppm) & $185.1 \pm 34.4$ & $213.3 \pm 28.2$ & $183.7 \pm 36.0$ & $158.3 \pm 19.4$ \\
\hline Sodium (ppm) & $3550.8 \pm 114.8$ & $3515.3 \pm 116.6$ & $3546.3 \pm 168.4$ & $3590.7 \pm 80.3$ \\
\hline Zinc (ppm) & $0.89 \pm 0.19$ & $0.78 \pm 0.10$ & $1.06 \pm 0.26$ & $0.83 \pm 0.02$ \\
\hline \multicolumn{5}{|l|}{ Vitamins } \\
\hline Retinol ( $\mu \mathrm{g} / \mathrm{ml})$ & $0.3 \pm 0.07$ & $0.2 \pm 0.08$ & $0.2 \pm 0.04$ & $0.3 \pm 0.08$ \\
\hline Tocopherol ( $\mu \mathrm{g} / \mathrm{ml})$ & $6.3 \pm 2.53$ & $5.5 \pm 1.95$ & $7.2 \pm 4.21$ & $6.3 \pm 1.31$ \\
\hline $25(\mathrm{OH}) \mathrm{D}(\mathrm{ng} / \mathrm{ml})$ & $43.3 \pm 18.3$ & $37.9 \pm 14.0$ & $56.9 \pm 26.3$ & $35.2 \pm 6.3$ \\
\hline
\end{tabular}

\section{Discussion}

We provide the first data on the health parameters of a wild population of Cebus capucinus, establishing baseline values for hematology, serum chemistry, enzymes, minerals, and parasites in a healthy population and providing an important reference point for evaluating the health of other wild populations. We also provide the first published information on appropriate Telazol doses for immobilizing and capturing wild Cebus capucinus. 


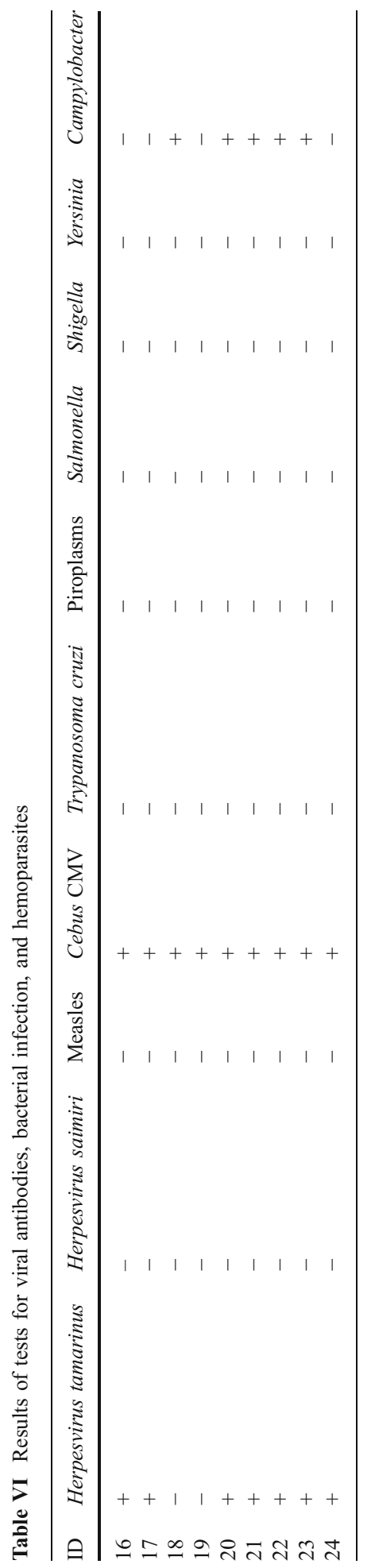


Table VII Results of testing for intestinal parasites by direct and floatation method

\begin{tabular}{lll}
\hline ID & Float results & Direct results \\
\hline 16 & NPS & NPS \\
17 & Unidentifiable larvae with very long & NPS \\
& thread-like tail & \\
18 & NPS & $72 \times 45 \mu \mathrm{m}$ very thick-shelled oval egg, rare \\
& & (r/o Macracanthorhynchus sp.) \\
19 & Unidentified larvae with long & NPS \\
& thread-like tail & \\
20 & NPS & Possible flagellate, rare \\
21 & NPS & NPS \\
22 & NPS & Ciliate cysts, mod; possible Macracanthorhyncus eggs \\
23 & Ciliate cysts, few & Ciliate cysts, rare \\
24 & NPS & Rare possible flagellate \\
\hline
\end{tabular}

\section{Immobilization}

The Telazol doses used in this and other studies of wild primates (Glander et al. 1991) are higher than those recommended for captive capuchins (Kreeger 1999). However, Karesh et al. (1998) suggest that it may be both possible and desirable to use lower doses of Telazol when chemically immobilizing wild-ranging primates. Following this recommendation, we lowered the Telazol dose administered from $26.3 \mathrm{mg}$ of Telazol $/ \mathrm{kg}$ to $17.5 \mathrm{mg}$ of Telazol $/ \mathrm{kg}$ in our last round of immobilizations. The lower dose successfully induced deep levels of anesthesia and provided sufficient time to collect samples and make measurements. However, decreasing the dosage did not shorten the capuchins' recovery periods. The primary effect of lower Telazol doses was an increase the latency between darting and immobilization.

Although it is perhaps surprising that decreasing Telazol doses by $33 \%$ did not have a measurable impact on the length of capuchin recovery periods, there are several possible explanations for this finding. First, the available pharmacokinetic data for Telazol indicate that its duration of action increases with dose but does not do so in a linear fashion (Semple et al. 2000). Thus, lowering Telazol doses by onethird will not result in a 33\% decrease in recovery periods. Second, several authors have noted considerable individual variation in responses to Telazol (Allen 1992; Haigh et al. 1985; Kreeger et al. 1990; Semple et al. 2000; Stirling et al. 1989). Finally, our behavioral, rather than physiological, definition of recovery may explain some of the variation we observed in the length of recovery periods. We defined recovery as the ability to climb unassisted, but it proved difficult to quantify and accurately measure the time required to reach this benchmark.

In our study, the benefits of lower drug doses did not outweigh the costs. With low doses, capuchins sometimes moved off after being darted, which made it difficult to find and recover them once the sedative took effect. Sedated individuals are vulnerable to both injury and predation if they are not found promptly, and although we successfully recovered all the capuchins we darted, the combined efforts of 5 people were needed to maintain visual contact with the darted individuals. The likelihood of successfully catching sedated capuchins in hammocks was higher when we could quietly observe individuals from a distance until they 
became heavily sedated. Higher Telazol doses helped ensure the safety of focal subjects by immobilizing them quickly, before they were lost from sight.

A frequent concern of primatologists who consider using chemical immobilization to fit radiocollars or collect biological samples is dishabituation of their focal subjects. Owing to the continuous presence of researchers at the Smithsonian Tropical Research Institute, the capuchins on Barro Colorado Island tolerated human observers even before a determined effort was made to habituate them. Regular behavioral observations on all 6 focal groups were conducted from June, 2004 to September 2005. At the time of the first round of darting, individuals were partially habituated, and by the second and third rounds, all focal subjects were fully habituated to the presence of human observers. However, after the first round of darting, despite habituation to other human observers, collared individuals were intolerant of the darter (R. G. Lessnau) or the dart gun. When Lessnau approached collared capuchins, they climbed into the canopy and fled.

Veterinary expertise is a critical component of wildlife anesthesia. Injuries and anesthetic emergencies are always a possibility when immobilizing wildlife, and researchers should be well prepared to handle such occurrences. Field equipment should include wound care supplies such as dilute iodine for flushing wounds, antibiotic ointment, basic surgical equipment and suture material, intravenous catheters, fluids, emergency drugs, endotracheal tubes, an $\mathrm{Ambu}^{\circledR}$ bag for ventilation, a laryngoscope, stethoscope, and portable pulse oximeter, bandage material, alcohol, gloves (sterile and examination), and face masks. Standard operating procedures should be established in advance for severe injuries requiring transport of the subject to a veterinary clinic for more intense therapy. Pathogen transfer from humans to primates should be minimized by wearing gloves and face masks, frequently washing hands, and not eating when in direct contact with the primates.

\section{Health}

Overall, the animals in this study were healthy and in good physical condition. Very little data exist on the mass and body measurements of wild capuchins, but our focal individuals were slightly heavier than those measured in Santa Rosa National Park, Costa Rica by Glander et al. (1991). On average, males on Barro Colorado Island (BCI) weighed $3.6 \mathrm{~kg}(\mathrm{SD}=0.8, n=7)$, vs. $3.3 \mathrm{~kg}(n=3)$ for males at Santa Rosa, and females on BCI weighed an average of $2.7 \mathrm{~kg}(\mathrm{SD}=0.3, n=13)$, whereas females at Santa Rosa averaged only $2.3 \mathrm{~kg}(n=3)$.

Capuchins from BCI had few intestinal or ectoparasites. Although previous studies have found relatively high rates of Trypanosoma cruzi infection in whitefaced capuchin populations in Panama (T. cruzi prevalence of 5\%; Sousa et al. 1974), none of the individuals in our study tested positive for the hemoparasite. Unfortunately, our sample size (24 individuals) was not large enough to determine whether the prevalence of Trypanosoma cruzi infection in the capuchins on Barro Colorado Island differed significantly from that reported by Sousa and colleagues (1974). The majority of capuchins in this study (7 of 9) were seropositive for Herpesvirus tamarinus, but this virus is not thought to have major negative consequences on white-faced capuchin health (Holmes et al. 1966). All individuals 
were seropositive for Cebus cytomegalovirus, which is known to have detrimental effects on the health of immunocompromised individuals (Bennett et al. 1998). However, the virus did not have an obvious negative impact on the capuchins in our study based on the normal results of the various diagnostics we performed. The percentage of individuals in our study missing $\geq 1$ tooth $(44 \%)$ is higher than has been previously reported for this species (8.3\%; Smith et al. 1977), but high rates of tooth loss and periodontal disease occur in other wild primate populations (Cuozzo and Sauther 2006; Phillips-Conroy et al. 1993).

We compared blood work obtained from our 9 subjects with physiologic normal clinical pathology values for the same species compiled by the International Species Information System (ISIS). We gleaned blood values for the species in the ISIS database from individuals at 4 zoological institutions; we combined all sexes and ages. Pooling of data from all ages and sexes, as well as the use of different cell and chemistry analyzers, may affect the accuracy of the means and standard deviations gleaned from the data. In general, values collected from the wild capuchins correlate well with those from the captive animal database. Notably, however, the percentage of eosinophils was greater for our focal subjects (mean $8.1 \%$; range 3-20\%) than those in the ISIS database (mean $2.9 \%$ ). This is most likely due to regular anthelminthic administration and parasite monitoring for captive individuals. In addition, capuchins in a regularly cleaned, relatively constant environment may be exposed to a smaller variety of antigenic stimuli that would induce a hypersensitivity-type response in the complete blood count.

Because developmental processes can influence complete blood count and blood chemistry, we compared the values for the 6 adults in our study to those for the 3 juveniles. Endogenous protein production increases as individuals mature, and normal adult values are expected at sexual maturity (Evans and Duncan 2003). We found that, as expected, total protein in the juveniles (mean $6.7 \mathrm{~g} / \mathrm{dl}$; range $6.2-7.0 \mathrm{~g} / \mathrm{dl}$ ) was notably less than that in the adults (mean $8.6 \mathrm{~g} / \mathrm{dl}$; range $7.2-9.7 \mathrm{~g} / \mathrm{dl}$ ). Similarly, the production and construction of bone during the growth of young animals is associated with increases in serum alkaline phosphatase. In these capuchins, juveniles had higher serum alkaline phosphatase values (mean $282.7 \mathrm{U} / \mathrm{L}$; range 192-369 U/L) than the adults (mean 120.3 U/L; range 68-185 U/L).

The juveniles and adults in our study showed an unexpected difference in serum potassium concentrations. Juveniles had a mean serum potassium concentration of $3.8 \mathrm{~g} / \mathrm{dl}$ (range 3.1-4.1 g/dl) while adult values ranged from 4.3-6.0 g/dl (mean $5.1 \mathrm{~g} / \mathrm{dl}$ ). There are no expected age or sex differences for this electrolyte (George 2003), and all values for this wild population fell within the reference points of the ISIS database. The vast majority of total body potassium is intracellular, and increases in serum potassium concentration may occur when hemolysis or other cell damage occurs during blood drawing (George 2003). Only 1 serum sample in our study exhibited hemolysis (subject 17), yet this individual's potassium concentration was in the low range for adults in our study. Low potassium levels may result from anorexia or loss through the gastrointestinal or urinary tracts but, because all capuchins in this study were in adequate body condition, insufficient food intake is not a likely cause of the age differences we observed in serum potassium levels. We think that the disparity in potassium values between juveniles and adults is most likely a result of random variation, but further study and an increased sample size are required to confirm this hypothesis. 
We observed a probable case of the congenital defect hypospadias in a juvenile male. The condition would be detrimental to and possibly inconsistent with reproduction in a wild primate. There is only a single other report of hypospadias in a nonhuman primate in the literature (Harrison 1976). However, it is not an uncommon congenital defect in human populations, with an incidence of 70 cases per 10,000 live births (Gallentine et al. 2001), and both genetic and environmental factors are thought to play a role in its etiology (Brouwers et al. 2007). The capuchin population on Barro Colorado Island is both small and genetically isolated. To understand how reproductive isolation is influencing population health, it will be important to continue monitoring the capuchins for genetic defects. In addition, study of the genetic diversity of the capuchins on Barro Colorado Island may be warranted, because the research could make an important contribution to our understanding of how forest fragmentation affects the health of small, isolated primate populations.

Health and disease are critical factors for understanding primate evolution and for developing effective conservation and management strategies. Health assessments of wild primates can provide important information on the incidence and prevalence of infectious disease, as well as surveying overall health status and elucidating variation both within and between populations. Because immobilizing and capturing wild primates is inherently risky for both the people and the study subjects involved, researchers should maximize the data they collect. As we demonstrate, it is easily possible to coordinate sample collections for health assessments with other research and management activities.

Acknowledgments We thank the Smithsonian Tropical Research Institute (STRI) and the Automated Radio Telemetry System Initiative, especially Oris Acevedo, Martin Wikelski, and Roland Kays for logistical support. We also thank Michelle Brown, Robyn Hoing, Jennifer Boothby, Robert Horan, Vilma Fernandez, George Middleton, Thomas Lambert, and Sheryl Staaden for help with darting; Nicanor Obaldia, DVM and Claudia Brandariz, DVM for veterinary support; Ann Bratthauer and Betty Ackerman for assistance analyzing samples; and Dennis Cote for help understanding the pharmacokinetics of Telazol. We thank Melissa Emery-Thompson, Zarin Machanda, Susy Cote, Linda Taylor, and Richard Wrangham for helpful comments and discussions on a previous draft of this paper. The Smithsonian Tropical Research Institute, the Frederik Sheldon Travel Grant, the American Society of Primatologists Small Research Grant, Sigma Xi, the Department of Biology, Armstrong Atlantic State University, and the Department of Biological Anthropology, Harvard University provided financial support for this work. The research described in this paper received clearance from the Harvard University IACUC (assurance number A-3593-1).

Open Access This article is distributed under the terms of the Creative Commons Attribution Noncommercial License which permits any noncommercial use, distribution, and reproduction in any medium, provided the original author(s) and source are credited.

\section{References}

Alexander, R. D. (1974). The evolution of social behavior. Annual Review of Ecology and Systematics, 5 , 325-383. doi:10.1146/annurev.es.05.110174.001545.

Allen, J. L. (1992). Immobilization of giant Chacoan peccaries (Catagonus wagneri) with a tiletaminehydrochloride zolazepam-hydrochloride combination. Journal of Wildlife Diseases, 28, 499-501.

Bennett, B. T., Abee, C. R., \& Henrickson, R. (1998). Nonhuman primates in biomedical research: Diseases. San Diego, CA: Academic Press.

Brouwers, M. M., Feitz, W. F. J., Roelofs, L. A. J., Kiemeney, L., de Gier, R. P. E., \& Roeleveld, N. (2007). Risk factors for hypospadias. European Journal of Pediatrics, 166, 671-678. doi:10.1007/ s00431-006-0304-z. 
Chen, T. C., Turner, A. K., \& Holick, M. F. (1990). Methods for the determination of the circulating concentration of 25-hydroxyvitamin D. The Journal of Nutritional Biochemistry, 1, 315-319. doi:10.1016/0955-2863(90)90067-U.

Crofoot, M. C. (2007). Mating and feeding competition in white-faced capuchins (Cebus capucinus): the importance of short- and long-term strategies. Behaviour, 144, 1473-1495. doi:10.1163/ 156853907782512119.

Crofoot, M. C., Gilby, I. C., Wikelski, M. C., \& Kays, R. W. (2008). Interaction location outweighs the competitive advantage of numerical superiority in Cebus capucinus intergroup contests. Proceedings of the National Academy of Sciences of the United States of America, 105, 577-581. doi:10.1073/ pnas.0707749105.

Cuozzo, F. P., \& Sauther, M. L. (2006). Severe wear and tooth loss in wild ring-tailed lemurs (Lemur catta): a function of feeding ecology, dental structure, and individual life history. Journal of Human Evolution, 51, 490-505. doi:10.1016/j.jhevol.2006.07.001.

Daszak, P., Cunningham, A. A., \& Hyatt, A. D. (2000). Wildlife ecology: emerging infectious diseases of wildlife: threats to biodiversity and human health. Science, 287, 443-449. doi:10.1126/ science.287.5452.443.

Davies, C. R., Ayres, J. M., Dye, C., \& Deane, L. M. (1991). Malaria infection rate of Amazonian primates increases with body weight and group size. Functional Ecology, 5, 655-662. doi:10.2307/ 2389485.

Deem, S. L., Karesh, W. B., \& Weisman, W. (2001). Putting theory into practice: wildlife health in conservation. Conservation Biology, 15, 1224-1233. doi:10.1046/j.1523-1739.2001.00336.x.

de Thoisy, B., Vogel, I., Reynes, J. M., Pouliquen, J. F., Carme, B., Kazanji, M., et al. (2001). Health evaluation of translocated free-ranging primates in French Guiana. American Journal of Primatology, 54, 1-16. doi:10.1002/ajp.1008.

Dutton, C. J., Junge, R. E., \& Louis, E. E. (2003). Biomedical evaluation of free-ranging ring-tailed lemurs (Lemur catta) in Tsimanampetsotsa strict nature reserve, Madagascar. Journal of Zoo and Wildlife Medicine, 34, 16-24.

Evans, E. W., \& Duncan, J. R. (2003). Proteins, lipids, and carbohydrates. In K. Latimer, E. A. Mahaffey, \& K. W. Prasse (Eds.), Veterinary Laboratory Medicine; Clinical Pathology (pp. 162-171). Ames, IA: Iowa State Press.

Gallentine, M. L., Morey, A. F., \& Thompson, I. M. (2001). Hypospadias: a contemporary epidemiologic assessment. Urology, 57, 788-790.

Garell, D. M., \& Meyers, D. M. (1995). Hematology and serum chemistry values for free-ranging golden crowned sifaka (Propithecus tattersalli). Journal of Zoo and Wildlife Medicine, 26, 382-386.

George, J. W. W. (2003). Water, electrolytes, and acid base. In K. Latimer, E. A. Mahaffey, \& K. W. Prasse (Eds.), Veterinary laboratory medicine; Clinical pathology (pp. 149-153). Ames, IA: Iowa State Press.

Glander, K. E., Fedigan, L., Fedigan, L. M., \& Chapman, C. (1991). Field methods for the capture and measurement of 3 monkey species in Costa Rica. Folia Primatologica, 57, 70-82. doi:10.1159/ 000156567.

Haigh, J. C., Stirling, I., \& Broughton, E. (1985). Immobilization of polar bears (Ursus maritimus Phipps) with a mixture of tiletamine hydrochloride and zolazepam hydrochloride. Journal of Wildlife Diseases, 21, 43-47.

Harrison, R. M. (1976). Hypospadias in a male rhesus monkey. Journal of Medical Primatology, 5, 60-63.

Holmes, A. W., Devine, J. A., Nowakows, E., \& Deinhard, F. (1966). Epidemiology of a herpes virus infection of New World monkeys. Journal of Immunology (Baltimore, MD.: 1950), 96, 668.

Junge, R. E., \& Louis, E. E. (2005a). Biomedical evaluation of two sympatric lemur species (Propithecus verreauxi deckeni and Eulemur fulvus rufus) in Tsiombokibo Classified Forest, Madagascar. Journal of Zoo and Wildlife Medicine, 36, 581-589.

Junge, R. E., \& Louis, E. E. (2005b). Preliminary biomedical evaluation of wild ruffed lemurs (Varecia variegata and V. rubra). American Journal of Primatology, 66, 85-94. doi:10.1002/ajp.20129.

Junge, R. E., \& Louis, E. E. (2007). Biomedical evaluation of black lemurs (Eulemur macaco macaco) in Lokobe Reserve, Madagascar. Journal of Zoo and Wildlife Medicine, 38, 67-76. doi:10.1638/06-006.1.

Kappeler, P. M., \& van Schaik, C. P. (2002). Evolution of primate social systems. International Journal of Primatology, 23, 707-740. doi:10.1023/A:1015520830318.

Karesh, W. B., \& Cook, R. A. (1995). Applications of veterinary medicine to in situ conservation efforts. Oryx, 29, 244-252.

Karesh, W. B., Wallace, R. B., Painter, R. L. E., Rumiz, D., Braselton, W. E., Dierenfeld, E. S., et al. (1998). Immobilization and health assessment of free-ranging black spider monkeys (Ateles paniscus 
chamek). American Journal of Primatology, 44, 107-123. doi:10.1002/(SICI)1098-2345(1998) 44:2<107::AID-AJP2>3.0.CO;2-\#.

Kondgen, S., Kuhl, H., N'Goran, P. K., Walsh, P. D., Schenk, S., Ernst, N., et al. (2008). Pandemic human viruses cause decline of endangered great apes. Current Biology, 18, 260-264. doi:10.1016/j. cub.2008.01.012.

Kreeger, T. J. (1999). Handbook of wildlife chemical immobilization (3rd ed.). Fort Collins, Colorado: Wildlife Pharmaceuticals, $342 \mathrm{pp}$

Kreeger, T. J., Seal, U. S., Callahan, M., \& Beckel, M. (1990). Physiological and behavioral responses of gray wolves (Canis lupus) to immobilization with tiletamine and zolazepam. Journal of Wildlife Diseases, 26, 90-94.

Loehle, C. (1995). Social barriers to pathogen transmission in wild animal populations. Ecology, 76, 326335. doi:10.2307/1941192.

Macdonald, D. W., \& Amlaner, C. J. (1980). A practical guide to radio tracking. In C. J. Amlaner, \& D. W. MacDonald (Eds.), A handbook on biotelemetry and radio tracking. Oxford: Pergamon Press.

May, R. M. (1988). Conservation and disease. Conservation Biology, 2, 28-30. doi:10.1111/j.15231739.1988.tb00332.x.

Moller, A. P., Dufva, R., \& Allander, K. (1993). Parasites and the evolution of host social behavior. Advances in the Study of Behavior, 22, 65-102. doi:10.1016/S0065-3454(08)60405-2.

Morner, T., Obendorf, D. L., Artois, M., \& Woodford, M. H. (2002). Surveillance and monitoring of wildlife diseases. Revue Scientifique et Technique de L'Office International des Epizooties, 21, 67-76.

Nunn, C., \& Heymann, E. (2005). Malaria infection and host behavior: A comparative study of Neotropical primates. Behavioral Ecology and Sociobiology, 59, 30-37. doi:10.1007/s00265-005-0005-z.

Phillips-Conroy, J. E., Hildebolt, C. F., Altmann, J., Jolly, C. J., \& Muruthi, P. (1993). Periodontal health in free-ranging baboons of Ethiopia and Kenya. American Journal of Physical Anthropology, 90, 359371. doi:10.1002/ajpa.1330900310.

Roellig, D. M., Ellis, A. E., \& Yabsley, M. Y. Oral transmission of Trypanosoma cruzi with opposing evidence for the theory of carnivory in the sylvatic cycle. The Journal of Parasitology, in press.

Scott, M. E. (1988). The impact of infection and disease on animal populations: Implications for conservation. Conservation Biology, 2, 40-56. doi:10.1111/j.1523-1739.1988.tb00334.x.

Semple, H. A., Gorecki, D. K. J., Farley, S. D., \& Ramsay, M. A. (2000). Pharmacokinetics and tissue residues of Telazol ${ }^{\circledR}$ in free-ranging polar bears. Journal of Wildlife Diseases, 36, 653-662.

Smith, J. D., Genoways, H. H., \& Jones, J. K. (1977). Cranial and dental anomalies in three species of platyrrhine monkeys from Nicaragua. Folia Primatologica, 28, 1-42. doi:10.1159/000155796.

Sousa, O. E., Rossan, R. N., \& Baerg, D. C. (1974). The prevalence of trypanosomes and microfilariae in Panamanian monkeys. The American Journal of Tropical Medicine and Hygiene, 23, 862-868.

Spalding, M. G., \& Forrester, D. J. (1993). Disease monitoring of free-ranging and released wildlife. Journal of Zoo and Wildlife Medicine, 24, 271-280.

Stirling, I., Spencer, C., \& Andriashek, D. (1989). Immobilization of polar bears (Ursus maritimus) with Telazol in the Canadian Arctic. Journal of Wildlife Diseases, 25, 159-168.

Vie, J. C., Moreau, B., de Thoisy, B., Fournier, P., \& Genty, C. (1998). Hematology and serum biochemistry values of free-ranging red howler monkeys (Alouatta seniculus) from French Guiana. Journal of Zoo and Wildlife Medicine, 29, 142-149.

Williams, E. S., Yuill, T., Artois, M., Fischer, J., \& Haigh, S. A. (2002). Emerging infectious diseases in wildlife. Revue Scientifique et Technique de L'Office International des Epizooties, 21, 139-157.

Wobeser, G. (2002). Disease management strategies for wildlife. Revue Scientifique et Technique de L'Office International des Epizooties, 21, 159-178.

Wrangham, R., Crofoot, M., Lundy, R., \& Gilby, I. (2007). Use of overlap zones among group-living primates: a test of the risk hypothesis. Behaviour, 144, 1599-1619. doi:10.1163/156853907782512092.

Yabsley, M. J., Murphy, S. M., \& Cunningham, M. W. (2006). Molecular detection and characterization of Cytauxzoon felis and a novel Babesia species in cougars (Puma concolor) from Florida. Journal of Wildlife Diseases, 42, 366-374. 